\title{
Introduction to Advances in Teaching and Learning Minitrack
}

\author{
David Spencer \\ New Jersey Institute of \\ Technology \\ dspencer@njit.edu
}

\author{
Timothy Ellis \\ Nova Southeastern University \\ ellist@nova.edu
}

\author{
Eric Santanen \\ Bucknell University \\ esantane@bucknell.edu
}

The Advances in Teaching and Learning Technologies minitrack encourages research contributions that deal with learning theories, cognition, tools and their development, enabling platforms, communication media, distance learning, supporting infrastructures, user experiences, research methods, social impacts, and/or measurable outcomes as they relate to the area of technology and its support of improving teaching and learning. Appropriate usage environments range from same-time, same-place to anytime, anywhere that increase interactions among the learners and the teacher/facilitator.
Special interest continues to focus on innovative ways of using social media to facilitate learning and its application to early childhood education. This minitrack is intended to include all aspects of teaching and learning technologies from the original inceptions of theories and tools through the measurement of learning outcomes. 